\title{
INDUSTRIAL ROBOT REPEATABILITY TESTING WITH HIGH SPEED CAMERA PHANTOM V2511
}

\author{
Jerzy Józwik', Dawid Ostrowski², Paweł Jarosz², Dariusz Mika² \\ 1 Department of Production Engineering, Mechanical Engineering Faculty, Lublin University of Technology, 36 \\ Nadbystrzycka Street, 20-816 Lublin, Poland, e-mail: j.jozwik@pollub.pl \\ 2 The State School of Higher Education, The Institute of Technical Sciences and Aviation, 54 Pocztowa Street, \\ 22-100 Chełm, Poland, e-mail: dostrowski@pwsz.chelm.pl, pjarosz@pwsz.chelm.pl, dmika@pwsz.chelm.pl
}

Received: 2016.07.06

Accepted: 2016.09.08

Published: 2016.12.01

\begin{abstract}
Apart from accuracy, one of the parameters describing industrial robots is positioning accuracy. The parameter in question, which is the subject of this paper, is often the decisive factor determining whether to apply a given robot to perform certain tasks or not. Articulated robots are predominantly used in such processes as: spot welding, transport of materials and other welding applications, where high positioning repeatability is required. It is therefore essential to recognise the parameter in question and to control it throughout the operation of the robot. This paper presents methodology for robot positioning accuracy measurements based on vision technique. The measurements were conducted with Phantom v2511 high-speed camera and TEMA Motion software, for motion analysis. The object of the measurements was a 6-axis Yaskawa Motoman HP20F industrial robot. The results of measurements obtained in tests provided data for the calculation of positioning accuracy of the robot, which was then juxtaposed against robot specifications. Also analysed was the impact of the direction of displacement on the value of attained pose errors. Test results are given in a graphic form.
\end{abstract}

Keywords: diagnostic, accuracy, robots, high speed camera.

\section{INTRODUCTION}

Application of industrial robots in manufacturing allows the enterprises to increase their competitiveness through shortening production cycles, reducing costs, increasing efficiency and improving flexibility of manufacturing. Different processes can be improved by selecting the proper combination of process parameters, machine tools and robots [10-12, 18]. Frequently, these machines are employed in operations where high precision is required, e.g. in machining or assembly. In such cases the knowledge of accuracy and repeatability parameters of a given robot is crucial $[4,6,9]$.

It is therefore important to establish proper test methodology. In industrial robots it proves particularly difficult, due to their complex kinematics and movements, which are performed in a multidimensional space. A standardised testing method for industrial robots is defined in ISO 9283:1998 [22]. The major problem in robot testing and diagnostics consists in the lack of proper testing and measurement equipment [7-9, 13-19]. This is by no means a problem in $\mathrm{CNC}$ multi-axis machine tools, where a wide range of diagnostic systems suitable for different applications are easily accessible [5-9]. This is confirmed by studies described in a relatively small number of existing research papers devoted to robot testing [2, 7-9, 13-17]. One of the most common testing methods applied in robotics is measurement with laser trackers. Among the advantages of the method is its capability to take measurements in multi-dimensional space $[2,4,13,17,21]$. In other studies, attempts have 
been made to apply methods dedicated for $\mathrm{CNC}$ machine tools, i.e. laser interferometry, which is similar to laser tracking, or telescopic ballbar testing. Although interferometers are characterised by much higher precision of measurement, their application in multi-axis articulated industrial robots is limited. This is predominantly on account of their limitations concerning linear measurements in one specified direction $[5,7,17,20]$. Similarly, in the case of ballbar instrumentation, the measurement can be taken only in a defined plane. In addition, the range of positioning errors in circular path tests (usually $1 \mathrm{~mm}$ ) frequently proves insufficient in large industrial robots testing applications [16, 17]. An interesting solution for robot error assessment is proposed in $[14,15]$, where a custom made instrument consisting of several ballbar extension bars enables error detection in a multi-dimensional plane. Thus constructed assembly provides high accuracy of measurements at a relatively low cost. However, the problem could be limited measurement range. Other methods for identification of positioning accuracy and repeatability errors employ e.g. 3D scanners [3] or multi-camera vision systems [1]. An example of such analysis is presented by authors of work [9]. In the study, photographic images were used to measure the distance between the reference needle and in the detection needle in robot's manipulator. The difference in distance measured in three axes gave the positioning repeatability parameter of the robot. The same vision method is applied in tests described in this paper. Due to technical capabilities of the method in question, the study focused on positioning repeatability of a selected industrial robot.
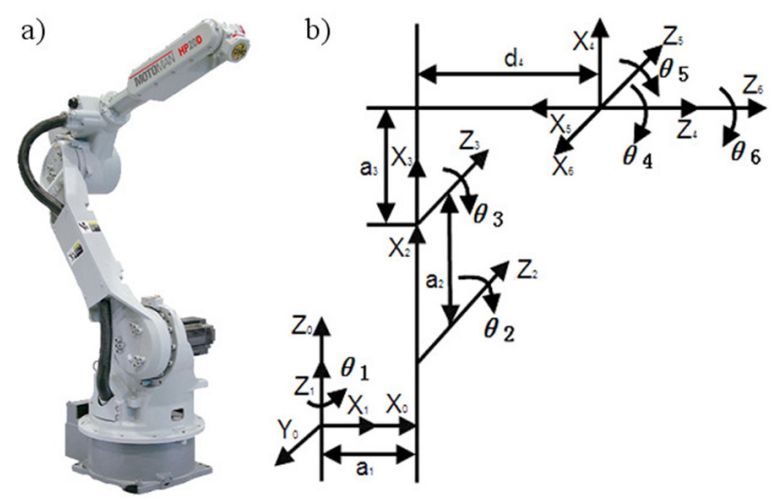

Fig. 1. HP20 industrial robot, a) overview, b) HP20 kinematic structure [19]

\section{EXPERIMENTAL TESTS METHODOLOGY}

The positioning repeatability tests were conducted on Yaskawa MOTOMAN HP20F six-axis industrial robot at the Environmental Research Laboratory in Centre for the Study Engineering of the State School of Higher Education in Chełm. The tested robot is characterised by high versatility and relatively high speed. HP20F is mainly used in: manipulation and assembly operations welding, palletisation, packaging or machine operation. The robot is programmed with FS100 Yaskawa controller. The kinematic structure of the robot is shown in Figure 1. Positioning repeatability declared by the manufacturer is equal to $0.06 \mathrm{~mm}$.

The test stand was surrounded by protective barriers, providing security and stable environmental conditions. The test were carried out with
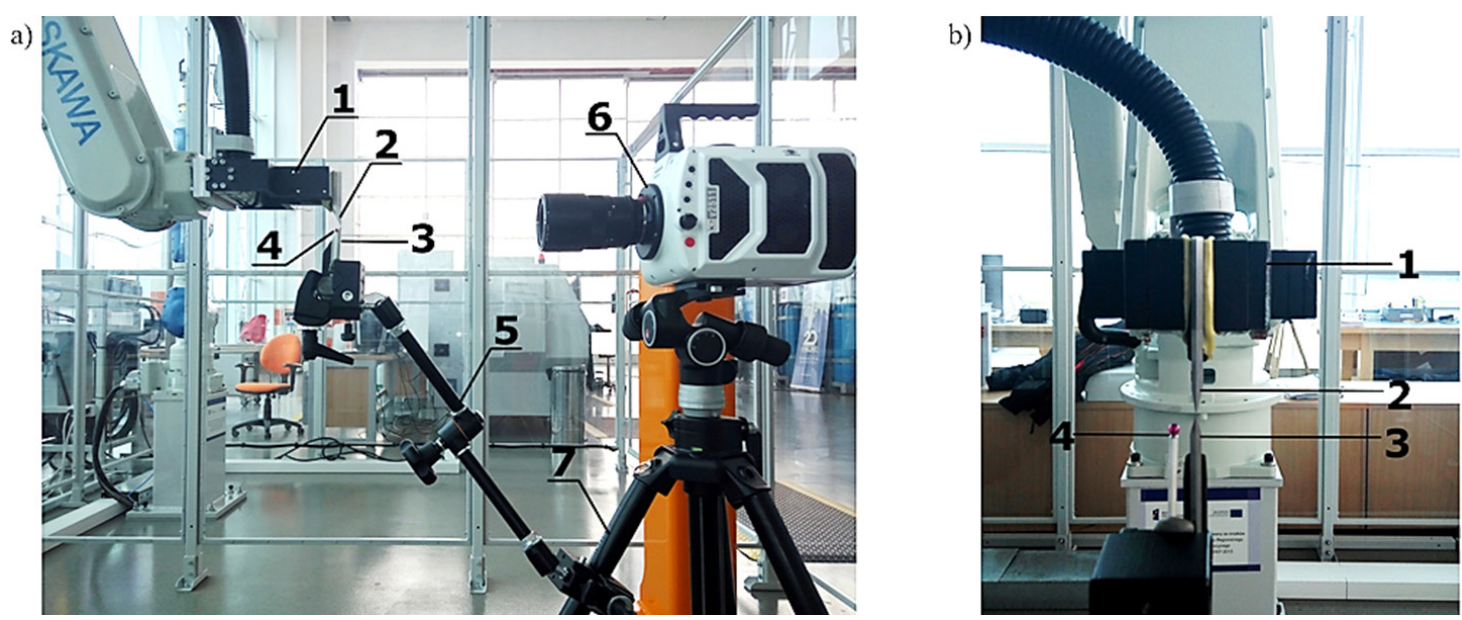

Fig. 2. Measurement set-up: a) side view, b) view in plane parallel to measuring plane XZ;

1- manipulator, 2- detection knife-edge rule, 3-reference knife-edge rule, 4- measuring probe head, 5-reference knife-edge rule stand, 6- Phantom v2511 high-speed camera equipped in micro lens 
Phantom v2511 high-speed camera, whose widescreen CMOS sensor allows the camera to acquire full high definition images $(1280 \times 800)$ at 25,000 frames-per-second $(25 \mathrm{kHz})$. At reduced resolution, it can provide frame rates of up to 677,600 fps.

The measurements consisted in registering the distance between two selected points in the $\mathrm{XZ}$ plane. One point was located on the tip of the knife-edge rule mounted on the measuring stand (reference). The other point was located on the tip of the knife-edge rule mounted on the robot's manipulator (detection). The measurement set-up is shown in Figure 2.

Robot's manipulator with a detection knifeedge rule moved to successive poses, specified in the measurement cycle. The cycle consisted in moving to a specified pose in the workspace and returning to the nominal pose, where it remained for $1.5 \mathrm{~s}$, during which the distance between tips of knife-edge rules was measured. The manipulator returned to nominal pose (P0) after each visit to specified poses. In tests, 8 poses were specified, after reaching of which the manipulator returned to nominal pose after linear motion from another direction (Fig. 3). The sequence of attained poses was as follows:

$$
\begin{aligned}
& \mathrm{P} 0 \rightarrow \mathrm{P} 1 \rightarrow \mathrm{P} 0 \rightarrow \mathrm{P} 2 \rightarrow \mathrm{P} 0 \rightarrow \mathrm{P} 3 \rightarrow \mathrm{P} 0 \rightarrow \mathrm{P} 4 \rightarrow \\
& \rightarrow \mathrm{P} 0 \rightarrow \mathrm{P} 5 \rightarrow \mathrm{P} 0 \rightarrow \mathrm{P} 6 \rightarrow \mathrm{P} 0 \rightarrow \mathrm{P} 7 \rightarrow \mathrm{P} 0 \rightarrow \mathrm{P} 8
\end{aligned}
$$

The number of cycles was limited to 8 , due to technical capabilities of the robot. Tests were carried out for the linear speed of manipulator motion equal to $750 \mathrm{~mm} / \mathrm{s}$. Each image was acquired at $100 \mathrm{fps}$, at the resolution of $1024 \times 768$ pixel. The object lens used in tests was Makro-Plannar 2/100 ZF.2 manufactured by Zeiss. Distance measurements (in the directions $X$ and $Z$ ) between tips of knife-edge rules were taken in XZ plane marked in blue in Figure 3.

The beginning of the coordinate system was specified at the tip of the reference knifeedge rule. TEMA Motion software automatically converted the distance from pixels to millimetres, and the only intervention required consisted in defining the scale coefficient by marking a distance and defining its actual length. A 5-mm reference ball of the measurement spindle was used (Fig 4). To prevent collision and damage, the nominal distance between the detection and reference tips were specified at: $0.058 \mathrm{~mm}$ in $\mathrm{X}$ direction and $1.250 \mathrm{~mm}$ in $\mathrm{Z}$ direction.

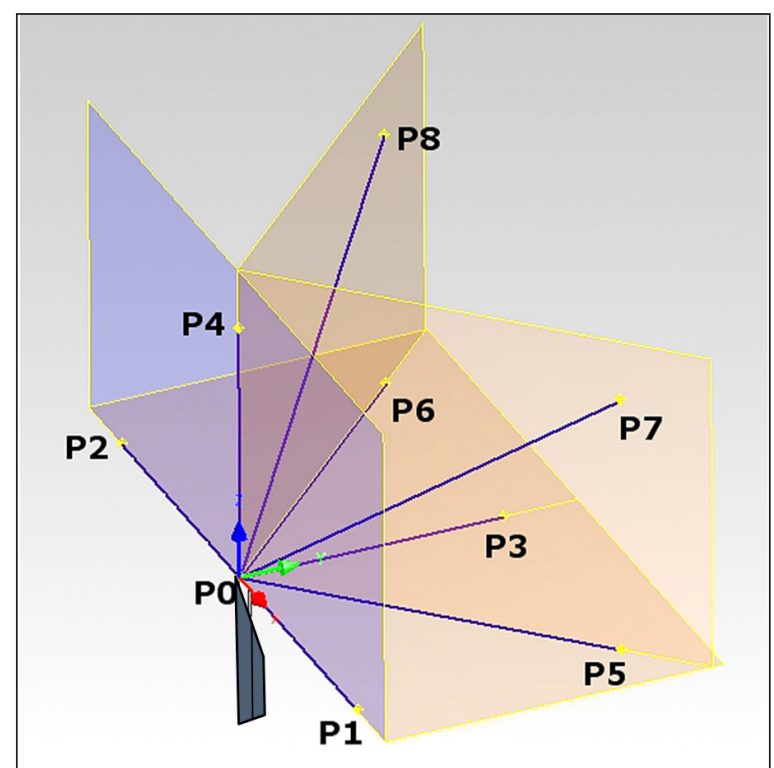

Fig. 3. Knife-edge rule travel in specified planes with marked poses, $\mathrm{P} 0$ - nominal pose, $\mathrm{P} 1 \div \mathrm{P} 8$ - attained poses and direction of approach

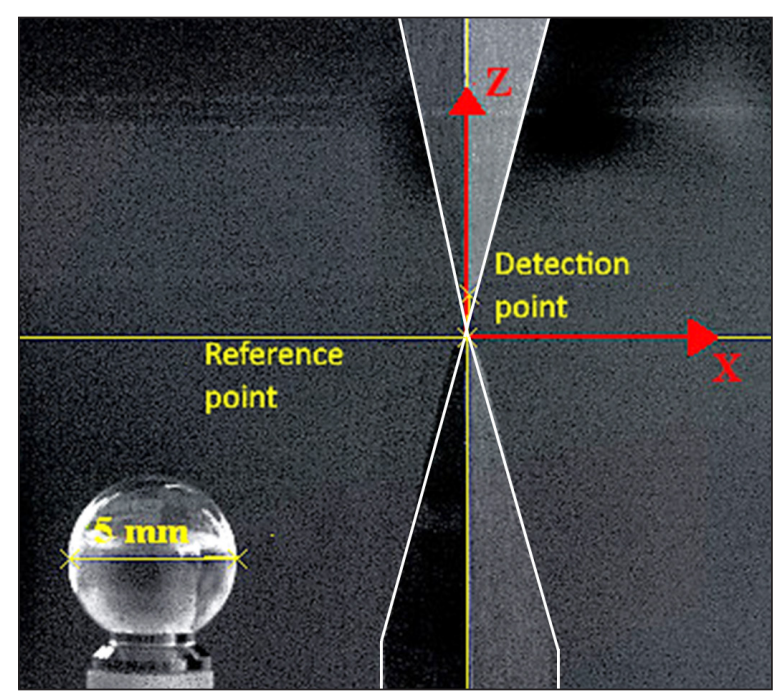

Fig. 4. View in measurement plane $X Z$

The measurement was automated by employing one of the software functions - tracking target points in motion. In tests, the edgeknife rule tip travels outside the frame, which required pausing tracking for a specified time interval. Automatic software registered the distance between tips (in $\mathrm{X}$ and $\mathrm{Z}$ directions) during the interval after returning to the nominal pose (P0).

\section{TEST RESULTS}

The analysis was carried out for measured positioning errors, i.e. deviation from the nominal 
distance between the reference and detection point $\left(\mathrm{X}_{\text {zad }}, \mathrm{Z}_{\text {zad }}\right)$ and actual distance $\left(\mathrm{X}_{\mathrm{i}}, \mathrm{Z}_{\mathrm{i}}\right)(1),(2)$.

$$
\begin{aligned}
& \Delta X=X_{i}-X_{z a d} \\
& \Delta Z=Z_{i}-Z_{z a d}
\end{aligned}
$$

Recorded error values are within the range $-0.047 \mathrm{~mm}$ and $+0.143 \mathrm{~mm}$ in the direction of $\mathrm{X}$-axis and $+0.029 \mathrm{~mm}$ to $+0.111 \mathrm{~mm}$ in the direction of Z-axis. Positioning errors measured in the direction of $X$-axis (Fig. 5) take both negative and positive values. In the case of Z-axis (Fig. 6), these were mainly errors in the positive values that were recorded. Moreover, with each measurement cycle the rising tendency of positioning error values in the Z-axis was observed.

Discrete values obtained in subsequent measurements were approximated with proper equations, i.e. (3) for $\mathrm{X}$-axis and (4) for Z-axis:

$$
\begin{gathered}
\Delta X=\mathbf{0 , 0 0 0 5} \cdot \mathbf{X}+\mathbf{0 , 0 1 0 2} \\
\Delta Z=1 \cdot 10^{-07} \cdot Z^{3}-\mathbf{3} \cdot 10^{-05} \cdot Z^{2}+\mathbf{0 , 0 0 2 5} \cdot Z-0,0067
\end{gathered}
$$

Figure 7 shows mean values of positioning errors $\Delta \mathrm{X}$ and $\Delta \mathrm{Z}$, measured in $\mathrm{X}$ and $\mathrm{Z}$-axis direc- tions in subsequent cycles. The values are within $0.037 \mathrm{~mm}$ and $0.057 \mathrm{~mm}$ in X-axis and $0.017 \mathrm{~mm}$ and $0.06 \mathrm{~mm}$ in Z-axis. In the case of errors in $Z$-axis, a higher fluctuation of mean values is observed in subsequent measurement cycles. In both cases, there is a marked rising tendency of mean error value in each subsequent measurement cycle. Simultaneously, the tendency is higher in the case of Z-axis measurements. In both cases, the lowest error was recorded in cycle 1 and the highest in cycle 5 .

Mathematical record of the of positioning error changes $\Delta \mathrm{X}_{\text {mean }}, \Delta \mathrm{Z}_{\text {mean }}$ is shown in equations (5) and (6) respectively

$$
\begin{aligned}
& \Delta \mathbf{X}_{\text {mean }}=\mathbf{0 . 0 0 2 4} \cdot \mathbf{X}+\mathbf{0 . 0 3 5}
\end{aligned}
$$

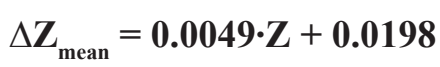

Analysis of obtained results showed the impact of the direction of approach to the nominal pose on the value and plus or minus sign of error value. This relationship can be observed e.g. in X-axis positioning error measurements (Fig. 8), where the approach to the nominal pose from the points to its right (P1, $\mathrm{P} 5, \mathrm{P} 7)$ produced errors with minus sign. In

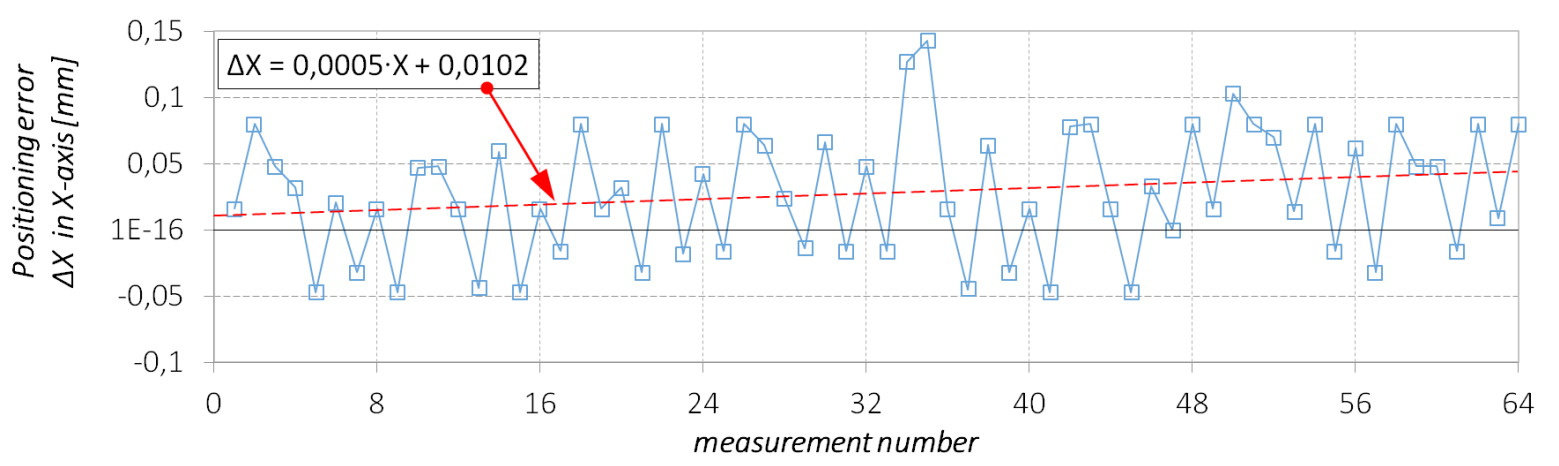

Fig. 5. Positioning error values $\Delta \mathrm{X}$ in $\mathrm{X}$-axis, in subsequent measurements at reaching nominal pose

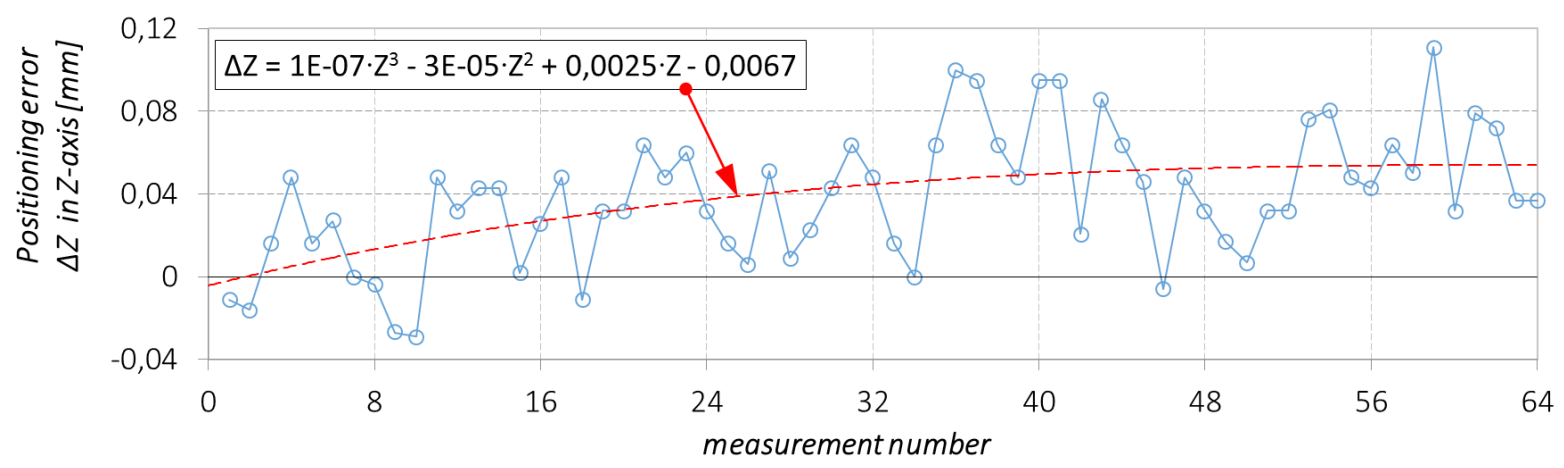

Fig. 6. Positioning error values $\Delta \mathrm{Z}$ in $\mathrm{Z}$-axis, in subsequent measurements at reaching nominal pose 


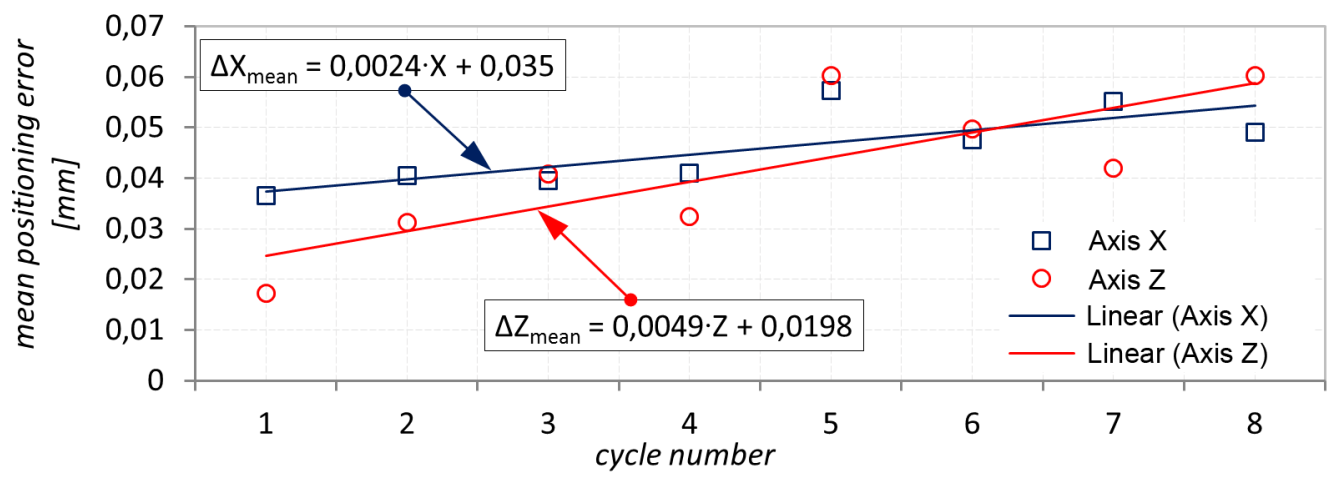

Fig. 7. Mean positioning error $\Delta \mathrm{X}_{\text {mean }}, \Delta \mathrm{Z}_{\text {mean }}$ measured in $\mathrm{X}$ and $\mathrm{Z}$-axis directions in subsequent measurement cycles

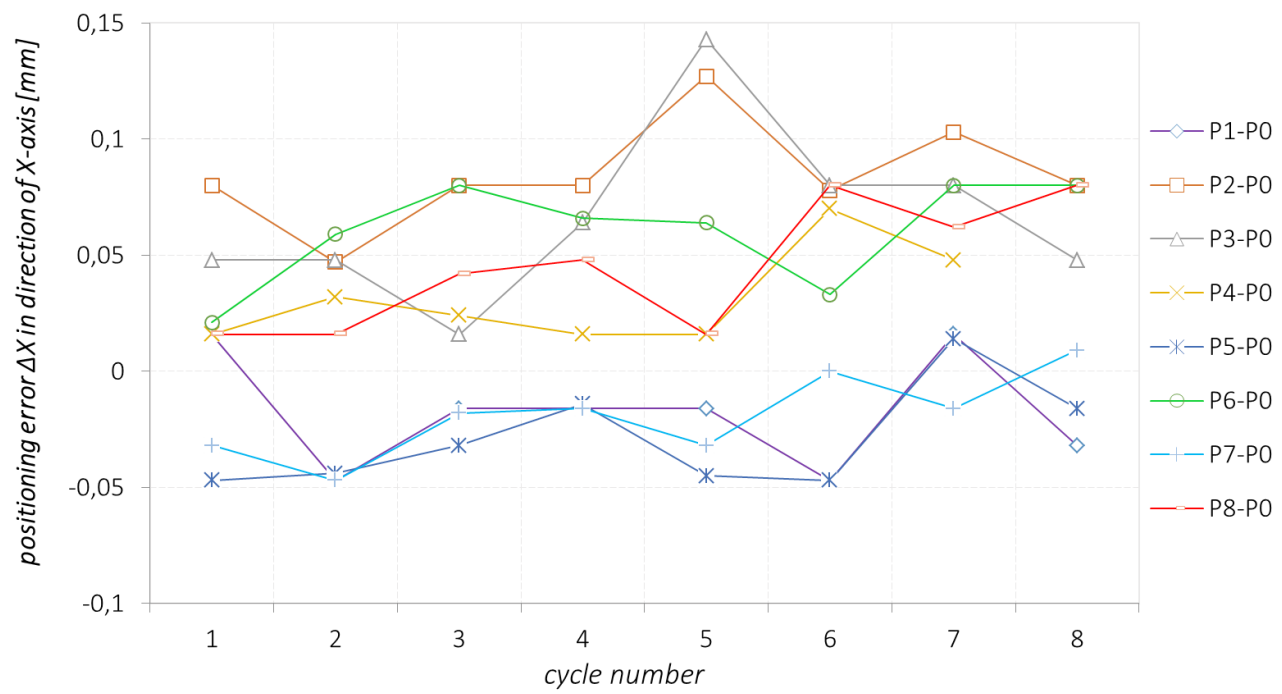

Fig. 8. Positioning error $\Delta \mathrm{X}$ in direction of $\mathrm{X}$-axis, measured after reaching nominal pose $\mathrm{P} 0$ from specified travel directions in subsequent measurement cycles

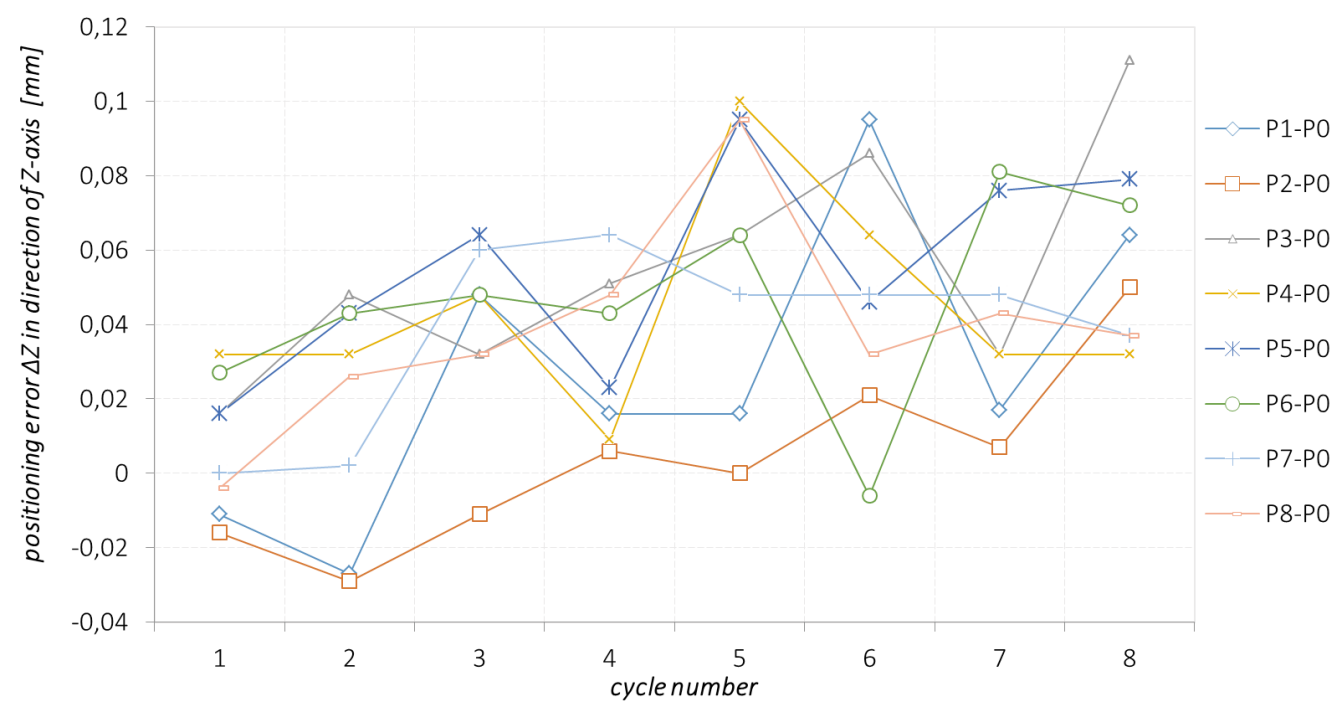

Fig. 9. Positioning error $\Delta Z$ in direction of $Z$-axis, measured after reaching nominal pose $P 0$ from specified travel directions in subsequent measurement cycles 


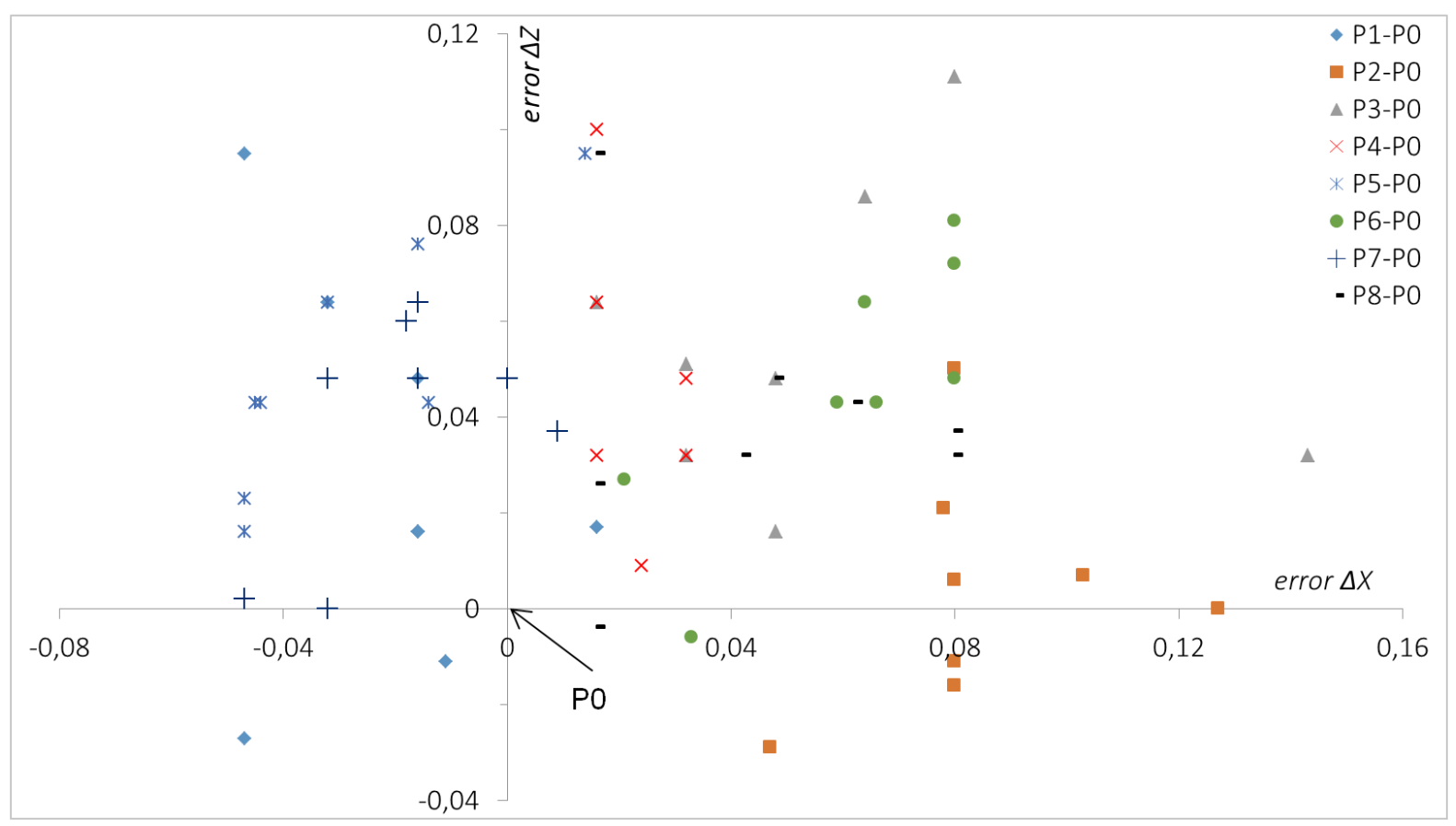

Fig. 10. Map of positioning errors $\Delta \mathrm{X}, \Delta \mathrm{Z}$ from nominal pose (P0) approached from different directions

the remaining cases recorded error values were only positive. An analogical diagram was created for positioning errors in Z-axis (Fig. 9), in which case both negative and positive error values were recorded. Notably, values of errors with positive sign were higher.

Analysing the map of deviations from the nominal pose P0 (Fig. 10), for each direction the nominal pose is approached from, we can observe characteristic positioning error values. The higher the scatter of error values, the worse the positioning repeatability.

Positioning repeatability is defined by the norm [18] as "the closeness of agreement between the attained poses after $n$ repeat visits to the same command pose in the same direction" and expressed by the following relationships (7) with (8), (9), (10):

$$
\boldsymbol{R} \boldsymbol{P}_{l}=\bar{l}+3 S_{l}
$$

where:

$$
\begin{gathered}
\bar{l}=\frac{1}{n} \sum_{j=1}^{n} l_{j} \\
l_{j}=\sqrt{\left(x_{j}-\bar{x}\right)^{2}+\left(y_{j}-\bar{y}\right)^{2}+\left(z_{j}-\bar{z}\right)^{2}} \\
S_{l}=\sqrt{\frac{\sum_{j=1}^{n}\left(l_{j}-\bar{l}\right)^{2}}{n-1}}
\end{gathered}
$$

with:

$\bar{x}, \bar{y}, \bar{z}-$ the coordinates of the bawcentre of the cluster of points obtained after repeating the same pose $\mathrm{n}$ times

$\mathrm{x}_{\mathrm{j}}, \mathrm{y}_{\mathrm{j}}, \mathrm{z}_{\mathrm{j}}$ - the coordinates of the J-th attained pose

Pose repeatability RP in each direction was calculated from relationships 7-10. Since the measurement was carried out in one plane at a time (non 3-D space) the calculations included $\mathrm{X}$ and $\mathrm{Z}$ components only. Results are shown in Figure 11.

Calculated values indicate the importance of direction from which the pose is attained on positioning repeatability. There can be distinguished directions which significantly reduce positioning repeatability parameter, e.g. P3-P0, P1-P0, where the parameter showed the lowest values, as well as directions where positioning repeatability RP is the highest. The difference between the highest and the lowest RP in selected directions is approx. $0.4 \mathrm{~mm}$. In the diagram (Fig. 11) red colour shows positioning repeatability $\mathrm{RP}_{\text {dec }}$ declared by the manufacturer in the robot's documentation. In each analysed direction of approach to the nominal pose the measured repeatability was higher than declared by the manufacturer. 


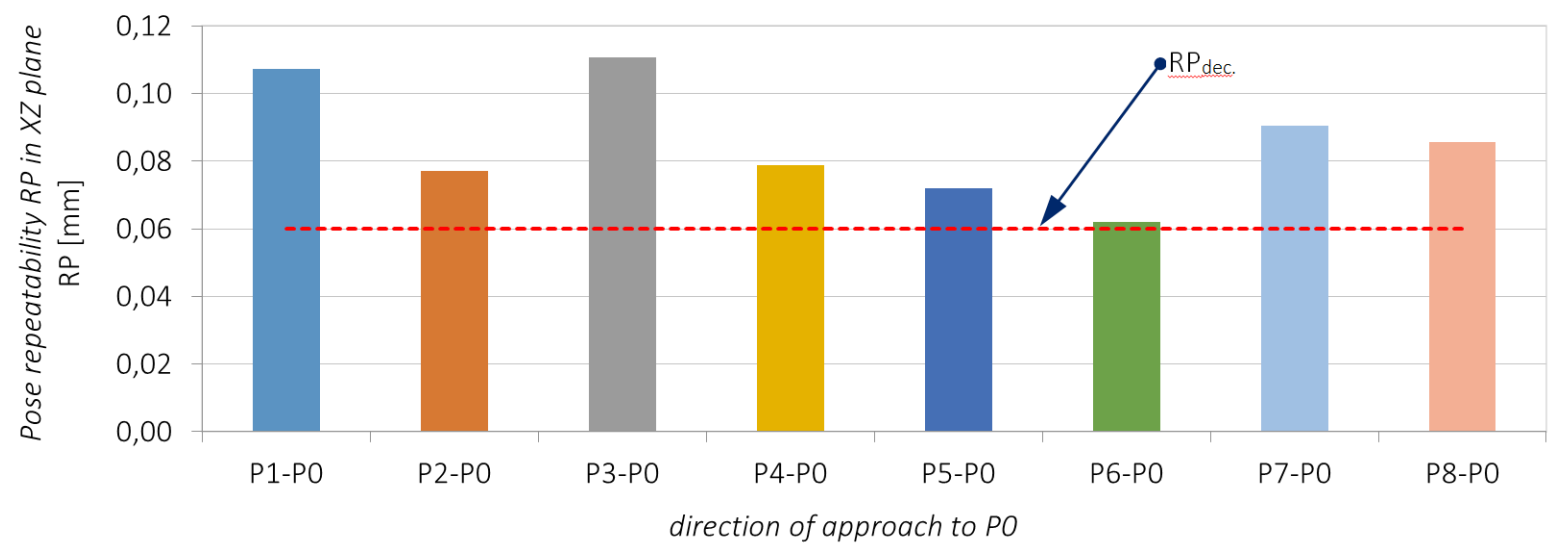

Fig. 11. Pose repeatability RP in XZ plane depending on the direction of approach

\section{CONCLUSIONS}

The paper presents contactless method for the determination of industrial robot's positioning repeatability, based on the use of high-speed camera and dedicated software for image analysis. The implemented method is a novelty in the field of industrial robot accuracy testing, whereas the study is among few in the field. The results obtained in the tests were accurate and promising, while the application of the method, even in industrial conditions, would be time-efficient and uncomplicated. Tracking target points in motion, which is one of the features offered by the applied measurement instrumentation, considerably facilitates data collection. Tracking is carried out as analysis of shades of individual pixels, therefore a suitable contrasting background should be provided for the objects between which the distance is measured (knife-edge rules). The presented method, however, is burdened with certain limitations, namely the possibility to measure errors in two directions at a time. This limitation results from measurements being taken in a selected plane. Still, the study shows that highspeed cameras with suitable software for image analysis can provide a great solution in robot positioning repeatability.

The analysis of obtained results indicates a rising tendency of positioning errors with each measurement cycle. This may result from thermal strain of the robot observed in continuous operation. This tendency can be nevertheless described mathematically with linear functions. The calculated positioning repeatability of tested robot indicates that the direction from which the robot's manipulator approaches the nominal pose is of considerable significance to robot's repeatability. Test results show that the repeatability parameter for each analysed direction of approach exceeded the level declared by the manufacturer, $R P_{d e c}=$ $0.06 \mathrm{~mm}$, and in several instances it nearly doubled the limit values. Mean positioning repeatability in all directions amounts to $0.06 \mathrm{~mm}$. The result indicates the need for calibration of the robot. Dynamic development of industry sets everhigher requirements for functional parameters of applied machines.

High repeatability of positioning is required by processes such as high-precision transport of elements, spot welding, and other welding applications. Similarly, in machining operations assisted by robots (manipulation and assembly of objects and tools), the parameter may be decisive for the dimensional and size accuracy of the finished product. The knowledge of positioning repeatability of available robots allows to take decisions with regards to including a particular robot in the manufacturing process, task scheduling, etc. Modern industrial robots offer high repeatability, which fulfils requirements of the majority of their applications. It must be remembered however, that the parameter is subject to change in prolonged operation of a robot. It is therefore essential to provide systematic and thorough control and maintenance of the robot's condition, which should include, inter alia, control of such parameters as accuracy or repeatability of positioning.

\section{REFERENCES}

1. Abderrahim M., Khamis A., Garrido S. and Moreno L. Accuracy and calibration issues of industrial manipulators. Industrial Robotics - Programming, 
Simulation and Applications (Low Kin Huat, (Ed.)), Verlag Robert Mayer- Scholz, Mammendorf, Germany, 131-146.

2. Alici G. and Shirinzadeh B. A systematic technique to estimate positioning errors for robot accuracy improvement using laser interferometry based sensing. Mechanism and Machine Theory, 40(8), 2005, 879-906.

3. Angelidis A. and Vosniakos G.Ch. Prediction and compensation of relative position error along industrial robot end-effector paths. International Journal of Precision Engineering and Manufacturing, 15(1), 2014, 63-73.

4. Głowacz A. Recognition of acoustic signals of synchronous motors with the use of MoFS and selected classifiers. Measurement Science Review, 15(4), 2015, 167-175.

5. Józwik J. and Czwarnowski M. Angular positioning accuracy of rotary table and repeatability of five-axis machining centre DMU 65 MonoBLOCK. Advances in Science and Technology Research Journal, 9(28), 2015, 89-95.

6. Józwik J., Semotiuk L. and Kuric I. Diagnostic of CNC lathe with QC 20 Ballbar system. Advances in Science and Technology Research Journal, 9(28), 2015, 96-102.

7. Józwik J., Ostrowski D., Wieczorek M. and Czwarnowski M. Evaluation of accuracy and positioning repeatability of an industrial robot. Advanced technologies in designing, engineering and manufacturing: Research problems,(T. Jachowicz, M. Kłonica, (Ed.)), Prefekta Info Renata Markisz, Lublin, Poland, 2015, 146-156.

8. Józwik J., Kuric I., Ostrowski D. and Dziedzic K. Industrial robot accuracy testing with QC20-W Ballbar diagnostic system. Manufacturing Technology, 16(3), 2016, 519-524.

9. Kiersztyn M., Wolszczak P. and Płaska S. Automatyczna kontrola pozycjonowania robota $\mathrm{w}$ elastycznym gnieździe wytwarzania z zastosowaniem technik wizyjnych. Mechanik, 87(8-9), 2014, 281-290.

10. Krolczyk G.M., Nieslony P., K Krolczyk J.B., Samardzic I., Legutko S., Hloch S., Barrans S. and Maruda R.W. Influence of argon pollution on the weld Surface Morphology. Measurement, 70, 2015, 203-213.

11. Krolczyk G.M., Krolczyk J.B., Maruda R.W., Legutko S. and Tomaszewski M. Metrological chang- es in surface morphology of high-strength steels in manufacturing processes. Measurement, 88, 2016, 176-185.

12. Maruda R.W., Krolczyk G.M., Feldshtein E., Szydlowski M., Legutko S., Pusavec F. and Sobczak-Kupiec A. A study on droplets sizes, their distribution and heat exchange for Minimum Quantity Cooling Lubrication (MQCL), International Journal of Machine Tools and Manufacture, 100, 2016, 81-92.

13. Nubiola A. and Bonev I. Absolute calibration of an ABB IRB 1600 robot using a laser tracker. Robotics and Computer - Integrated Manufacturing, 29(1), 2013, 236-245.

14. Nubiola A., Slamani M. and Bonev I. A new method for measuring a large set of poses with a single telescopic ballbar. Precision Engineering, 37, 2013, 451-460.

15. Nubiola A. and Bonev I. Absolute robot calibration with a single telescoping ballbar. Precision Engineering, 38, 2014, 472-480.

16. Slamani M., Joubair A. and Bonev I. A comparative evaluation of three industrial robots using three reference measuring techniques, Industrial Robot. An International Journal, 42(6), 2015, 572-585.

17. Slamani M., Nubiola A. and Bonev I. Assessment of the positioning performance of an industrial robot. Industrial robot: An International Journal, 39(1), 2012, 57-68.

18. Wojciechowski S., Chwalczuk T., Twardowski P. and Krolczyk G.M. Modeling of cutter displacements during ball end milling of inclined surfaces. Archives of Civil and Mechanical Engineering, 15(4), 2015, 798-805.

19. Wu K., Brueninghaus J., Johnen B. and Kuhlenkoetter B. Applicability of stereo high speed camera systems for robot dynamics analysis. International Conference on Control, Automation and Robotics, 2015, 44-48.

20. Young K. and Pickin C.G. Accuracy assessment of the modern industrial robot. Industrial robot: An International Journal, 39(6), 2000, 427-436.

21. Zhenhua W., Hui X., Guodong CH., Rongchuan S. and Sun L. A distance error based industrial robot kinematic calibration method. Industrial Robot: An International Journal, 41(5), 2014, 439-446.

22. ISO 9283:1998 Manipulating industrial robotsPerformance criteria and related test methods.

23. www.robotraders.co.uk (24.07.2015). 